\section{Goffman and Spoiled Identity: Helping Developmental Students Shed the Label}

\author{
Jack Trammell
}

\section{ABOUT THE AUTHOR}

Jack Trammell is visiting Associate Professor of Sociology and Anthropology at RandolphMacon College in Ashland, Virginia. He specializes in disability, learning assistance theory and practice, and stigma.

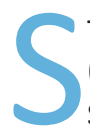

tudents who are in developmental education (DE), like students with disabilities and other students receiving learning supports, are often identified as such a priori, which means the students have already lost control over a certain amount of information about their identities. This is done in any number of ways, ranging from the quantitative criteria used to place students into DE tracks to the actual label that some programs use to signify and formalize inclusion. Sometimes the consequences for carrying such a label are minor-perhaps students have a coded number on a transcript that generally will not be seen as a negative factor-although sometimes the consequences are more serious: a student may feel marginalized by the attitudes that others have on campus in relationship to the label.

In the Goffman identity management paradigm, these students are already at risk simply by the loss of control over this personal information (Goffman, 1963). In his own words, the students find that their role has already been created for them: "a particular front has already been established" (Goffman, 2013, p. 27). By its very definition, the label brings with it stigma, social consequences, and most importantly perhaps for this conversation, educational consequences over which the student may have little control and which may significantly and adversely impact their success (Trammell, 2009).

On the surface, this assumption seems to be partially irrelevant-if learning support cannot occur until students are identified, then why bother conversing about the label? The label is often a necessary step. For this perfectly justifiable reason, learning assistance programs and DE have generally focused pri- marily on academic interventions, like tutoring, and not as much on the significant impact of the at-risk label (Bremer et al., 2013). But if Goffman is correct in his global assumption that "stigma management is a general feature" anywhere there is deviation from the norm, then perhaps educators in DE and learning assistance professionals have not spent enough time designing programs and helping students avoid some of the more serious and potentially harmful consequences of being forced to wear the at-risk student "mask" (Goffman, 1963, p. 130). In other words, they are not empowered with information management techniques that position them to limit stigma and educational consequences.

\section{Three-Fold Intervention}

Goffman's (1963) work, along with many others directly involved in educating students who are at-risk, suggested three areas where administrators as well as educators in DE can focus interventions. First, at the macro level, an intensive examination of the program -its forms and protocols, its position of normalcy within the entire school, and how the label (in the data management sense) is positioned in recordkeeping-can readily be assessed for impact as a positive or negative reinforcement of the label. The power of semantics in designing and implementing programs should never be underestimated. Although arguably no permanent language is correct for all politics and circumstances, a general sensitivity to language can reveal subtle opportunities to reverse negative representations and grow more positive ones.

At the micro level, students should be taught and then encouraged to cultivate their own information-management skills (Trammell, 2010). Students should be aided in having an accurate understanding of their own abilities and potentialities, and in some cases, direct information about what the label means at their school. Students should be taught how to communicate with others about their learning situation: Who do I tell? When do I tell? How much do I tell? Why do I tell? How do I process my own perspective about the "mask?" Ideally, this variation on the theme of self-advocacy should begin much earlier than the postsecondary experience.

Between the micro and the macro, the training of staff is an effective level to address the power of the label. From peer tutors to classroom instructors, most have not fully thought through the full implications of the labels that the students have as part of their at-risk identity at school. Training and awareness of labeling theory for faculty and staff can bear immediate fruits, including discovery of their own forms of information management (since they handle student's information, and faculty and staff have their own diversity to balance). 


\section{Conclusion}

Perhaps, as Goffman suggests, there is no way to escape the necessity of the label. Whether that is true or not, DE programs and other learning assistance initiatives should use the power of identity and information management to ensure positive experiences and academic success for students. All three of these areas are important but by themselves still cannot change the initial effect of the label completely. By definition, the students are at risk. And the definition reifies that risk. But we, as learning assistance professionals, are also in powerful positions of authority where we can challenge the labels and train accordingly.

\section{References}

Bremer, C. D., Center, B. A., Opsal, C. L., Medhanie, A., Jang, Y. J., \& Geise, A. C. (2013). Outcome trajectories of developmental students in community colleges. Community College Review, 41(2), 154.

Goffman, E. (1963). Stigma: Notes on the management of spoiled identity. Englewood Cliffs, NJ: Prentice-Hall.

Goffman, E. (2013). Performances. In P. Kivisto (Ed.), Social theory: Roots \& branches, (5 $5^{\text {th }}$ ed.). New York, NY: Oxford University Press.

Trammell, J. (2009). Red-shirting college students with disabilities. Learning Assistance Review (TLAR), 14(2), 21-31.

Trammell, J. (2010). Teach students with disabilities how to become better information managers. Disability Compliance for Higher Education, 15(6), 7. 